\title{
Transforming research on morphology into teacher practice
}

Jane Hurry, Terezinha Nunes, Peter Bryant, Ursula Pretzlik, Mary Parker, Tamsin Curno \& Lucinda Midgely

\begin{abstract}
Research suggests that the explicit teaching of morphological principles will improve children's spelling. Despite the fact that reference is made to morphology in English policy documents, teachers make limited use of morphology when teaching spelling, relying more heavily on phonic and visual strategies. After attending a course on role of morphemes in spelling, teachers' own awareness of morphology increased and this was reflected in their practice. This in turn caused their pupils to make significant gains in spelling, compared to a control group. This reinforces the proposition that explicit instruction about morphemes is helpful to children's learning. It demonstrates the fact that research can be transformed into teacher practice, but it also illustrates the difficulties. Policy documentation alone is insufficient. Professional development can effect change but this may be hard to sustain. Children's gains are contingent on teacher's continuing to dedicate class time to focussed intervention.
\end{abstract}

Key words: morphology, teacher practice, professional development, spelling 


\section{BACKGROUND}

\section{The role of morphemes in children's reading and spelling}

Our starting point is a desire to improve children's literacy skills. We have taken a particular theoretical position, that enabling children to understand underlying principles will be a powerful way of improving their performance in practical tasks. Foregrounding the power of conceptual understanding has a long tradition (eg. Piaget, 1978; Karmiloff-Smith, 1992). In the context of literacy, the importance of understanding the alphabetic principle is a well-known example of the significance of conceptual understanding (eg. Frith, 1985). A less well-researched concept, which is our focus here, is that of morphology.

A morpheme is the smallest part of a word that carries meaning, so that can be a whole word, like "cat" or just part of a word like the "s" in "cats" or the suffix "less" in "careless". Our language is a morphological jigsaw which we manipulate all the time to increase our word power: eg. verbs created from nouns - paint balling, texting, etc. But despite the fact that morphemes are one of the key building blocks of words in any language, many of us are unconscious of our morphological expertise. This is frequently the case with skills that are learnt early in our development. We argue that if children's attention is explicitly drawn to the morphemic structure of English it will provide a conceptual base which will support their learning to read and spell. 
The role of morphemes in helping children read is relatively under-researched. Dual route explanations of the reading process (Jackson \& Coltheart, 2001) consider the recognition of whole words or letter strings (which could be morphemes) as one of the two routes used to recognise the printed word (the lexical route). However, there is no real interest in morphemes as a special case of the lexical route. Phonology and analogy have dominated work in this area. However, research in spelling has explored the role of the morpheme. Treiman and Cassar (1997) summarise the principle developmental theories of spelling development (Ehri, 1986; Gentry, 1982; Henderson, 1985). They differ in some details but they all recognise that early spelling development is characterised by an increasing use of phonic strategies. As spellers mature, they build a greater repertoire of sight spelling and begin to understand the meaning relations among words which they use to help them spell. For example, Ehri (1986) identifies three broad stages of spelling development:

1. Semi-phonetic: Spellers represent sounds or syllables with letters that match their letter names: R (are), U (you), LEFT (elephant)

2. Phonetic: The child can symbolise the entire sound structure of words in their spellings but the letters are assigned strictly on the basis of sound (Treiman and Cassar, 1997).

3. Morphemic: The child becomes more aware of conventional spelling, employing visual and morphological information in spelling. For example, children learn to represent the ' $t$ ' sound at the end of past tense regular verbs with 'ed' (Nunes, Bryant \& Bindman, 1997). 
There is a debate about when children start to use their knowledge of morphemes in their spelling. Treiman, Cassar and Zukowski (1994) find some evidence of five year olds using simple morphological relations to guide their spelling. Nunes, Bryant and Bindman (1997) suggest that seven and eight year old children are entering the morphemic stage in spelling. Henderson (1985), who writes about derivational spelling (eg. "heal" and "health", "confide", "confident" and "confidential"), suggests that children do not start applying these principles until around 10 or 11 years old. In fact, the ramifications of the function of morphemes in English are considerable and it seems probable that children's understandings of morphemes and word derivations develop over a number of years, possibly well into adulthood (eg. Nunes, Bryant and Bindman, 1997). Nonetheless, there is some consensus that from the age of 7 years onwards children can certainly benefit from explicit instruction in morphology (Treiman and Cassar, 1997). Our research with children confirms that teaching them about morphemes produces significant gains in spelling (Nunes et al, 2003).

\section{Teaching morphology}

No matter how well researchers may think they know how to improve aspects of children's learning, these techniques have to be made available in the classroom to have any lasting impact. The case of explicit phonics instruction in the first years of school is a chastening example of this. Researchers have been demonstrating the value of the explicit instruction of phonics since the 1930s but the practice has only been securely evident in schools since the 1990s (Hurry, 2004). The process of transforming research into practice is complex and varies according to the systems in place to manage education. However, very broadly, this process must incorporate both macro and micro levels. It must be visible at a national or policy level and within 
classrooms. The role of morphology in literacy has not been extensively researched and might therefore have a relatively low profile at both levels.

\section{Policy about morphology}

School practice is regulated by centralised assessments, curriculum and curriculum materials. Since the English system of teaching literacy is centrally defined through the National Curriculum and the more detailed and practically oriented National Literacy Strategy (NLS), the place of morphology is reasonably transparent. Both of these sets of policy documentation mention morphology. The National Curriculum promotes teaching morphemes in the context of spelling (eg. National Curriculum online (2004), Programme of Study for Key Stage 2 EN3 Writing). Of ten named areas that "pupils should be taught", three relate to morphology and the term morphology is explicitly headlined. In the NLS documentation, morphemes are identified as one of the principles underpinning word construction, and are seen as having a place in teaching spelling (DfEE, 1998; DfES, 2001; DfES, 2003). For example, in the Year 2 and 3 Planning Exemplification and Spelling Programme (DfES, 2003), two activities out of 13 involve morphemic strategies. However, at this more detailed and practical level, the word morpheme is not used. Also, in the same document, children are advised to try three strategies if they do not know how to spell a word; sounding out or breaking into syllables; finding words which sound the same; looking it up in a spelling log or dictionary. Finding root words or thinking about morphemes are not mentioned. As policy moves more closely to practice more detail must be documented and emphasis begins to become apparent. 
It is also important to acknowledge that centralised policy is limited in its influence over what happens in the classroom. Elmore (1996) has argued in the US context that even the most successful centralised educational reforms rarely influence more than $25 \%$ of classrooms.

\section{$\underline{\text { Teacher practice }}$}

National policies and initiatives are only one of the significant external factors. School policies and structures also determine what happens in the classroom, a fact which led Adey (2004) to remark on the "futility of trying to change teaching practice by working with just one or two teachers from a school". However, the teacher's own plans, practices, knowledge and beliefs also have an impact on children's learning in many domains, including literacy (eg. Clark and Peterson, 1986; Fisher et al, 1994; Grossman, 1990; Shulman, 1987; Zancanella, 1991).

We have a particular interest in teachers' knowledge. As mentioned above, in the context of the primary or elementary school curriculum, adults tend to have implicit rather than explicit knowledge of fundamental concepts. Within our framework, we argue that the explicit knowledge of these concepts is not only a powerful aid to learning, but also to teaching. Lack of consciousness of the underlying principles one applies to read, spell and do arithmetic becomes an issue when one has to teach these skills. Thus, the first step in transforming our research with children into teachers' practice is to ensure that teachers have explicit knowledge of the role of morphemes in reading and spelling. This has been referred to as content knowledge (Shulman, 1987) and can be seen as the " 'stuff' of a discipline: factual information, 
organizational principles, [or] central concepts" (Grossman, Wilson \& Shulman, 1989, p.27).

Increasing teachers' explicit content knowledge is unlikely to be sufficient to change their practice. They need to be convinced that it is valuable to teach their pupils about morphology, they need to know how to do it, they need to have the resources to do it and they need to feel that it is sanctioned by the educational frameworks within which they operate.

To persuade teachers of the value of teaching morphology explicitly, they need to be informed about the research base, but ideally also to see how it works in their own classroom. The importance of teacher motivation in the process of educational change is well recognised (eg. Leithwood, Begley \& Cousins, 1992; O’Day, 1996).

To know how to teach about morphemes, teachers need to transform their conceptual understanding into forms that make sense to their students (Shulman, 1987). Shulman argues that "the knowledge base of teaching lies at the intersection of content and pedagogy" (1987, p.15). He invented the term "pedagogical content knowledge" to encapsulate this fusion between knowledge of pedagogy and knowledge of content. Joyce and Weil (1986) argue that the knowledge which underpins skilled practice develops through repeated cycles of (i) developing a conceptual knowledge structure, (ii) teaching a lesson guided by this knowledge structure, (iii) obtaining feedback about the adequacy of the teaching strategies, (iv) refining the knowledge structure. They estimate that teachers need 30 hours of practice to perfect a new teaching technique. 
The provision of resources to teach about morphemes will make it easier for teachers to enter this cycle, both practically, in the sense that some of the work is done for them, but also conceptually, as the materials can provide more detail about the role of morphemes in children's learning. It is the nature of conceptual understanding that it involves making multiple connections between existing aspects of knowledge. Concepts cannot simply be transmitted, they need to be assimilated and accommodated (to use Piaget's terminology).

Fortunately, teaching morphology is sanctioned by the educational framework within which English teachers operate. However, this needs to be made clear to teachers.

\section{Aims of the study}

In this study, we first wish to explore the extent of teachers' explicit knowledge of morphology and their reference to morphology in their practice. We then want to see if we can increase both their knowledge and their reference to morphemes in their teaching of spelling. In our evaluation of this professional development we will document both teachers' reactions to the course and its impact on their pupils' spelling.

\section{METHOD}

\section{Research Design}

The research was carried out in two phases. In the first phase, a survey was conducted to document teachers' awareness of morphology. Teachers were interviewed 
concerning their knowledge and practice of children's spelling and were observed (usually videotaped) during one literacy hour. The second phase involved a quasiexperiment. Teachers were invited to attend a ten-session course focussing on morphology and comprehension. A further group of teachers was recruited as a comparison, drawn both from the same schools as the teachers on the course and from teachers attending a similar course on numeracy. Assessments were made at the beginning and end of the course of the teachers' knowledge and practice and of their pupils' spelling. Teachers also kept diaries.

\section{Phase one - survey}

\section{$\underline{\text { Sample }}$}

Fifty-one teachers were recruited from 13 inner-London state primary schools. Their pupils were aged between 7 and 11 years old (Key Stage 2). Children tended to be of lower than average socio-economic status, ethnically diverse and with a relatively high proportion for whom English was an additional language.

\section{$\underline{\text { Interviews }}$}

Interviews were designed to reveal teachers' working knowledge and practice, their pedagogical content knowledge. They were therefore asked quite concretely about the difficulties their pupils had with spelling, and the ways in which they would address these difficulties. The teachers were presented with the following list of words which illustrate a range of challenges for spellers: White, Opened, Pavement, Baseball, Richness, Motion, Combination, Slept, Prepare, Smoke, Dark, Uncovered. For each word, they were asked what sort of errors their pupils would make, what they thought 
were the underlying reasons for these errors and how they would teach the children to help them correct their mistakes.

\section{$\underline{\text { Observation }}$}

Each teacher was observed for one literacy hour, normally recorded on video-tape (46 teachers were video-taped). These observations were then analysed using a number of dimensions, including a description of the main teaching events covered during the lesson, the teacher's objectives and the key concepts addressed.

\section{Phase two - quasi-experiment}

\section{$\underline{\text { Sample }}$}

\section{Teachers}

Teachers were recruited from inner-London primary school. Twenty-two teachers and three Literacy Advisors attended the course.

\section{Children}

Seventeen of the teachers attending the course assessed their children at the beginning and end of the course (the 'Morphology group'). We also collected similar data from 15 classes where the teacher had not attended the course (the 'Control group'). The control classes were recruited from the schools of the teachers attending the course $(n=8)$ and from classes taught by teachers who had attended a similar course focusing on numeracy $(\mathrm{n}=7)$ in the previous term. Table 1 shows the numbers of children in these two groups by year group.

Table 1 around here 


\section{$\underline{\text { Data collection }}$}

\section{Teachers}

At the beginning of the first session we asked teachers to write down the strategies they used to teach spelling and their definition of a morpheme. They then discussed their responses as a class and this was also recorded. This served the dual function of allowing us to document the teachers' practice before intervention and to facilitate group discussion about teaching spelling. This procedure was repeated at the last session, where teachers were also asked to work in groups to prepare posters on the intervention process (how it worked in class, issues around the course, strengths and weaknesses, influence on their practice, etc.). Plenary discussions were video-taped. Teachers were also asked to keep diaries of the morphology sessions in their classrooms.

\section{Children}

The children were assessed using two specially devised spelling tests. The first test was made up of 32 words, all but 5 of which contained at least one of the morphemes targeted by the intervention (spelling test). The second test comprised 10 invented words which also included the target morphemes (pseudo-word spelling test). Children could only spell the words in this second test correctly by applying the rules, as they had never seen the words before. Full marks were given for a correct spelling, partial marks for incorrect spellings where the morpheme was correctly spelt and no marks for words with incorrectly spelt morphemes. Scores were then converted to percentages to make them easier to interpret. Both tests had high internal consistency (alpha for spelling test $=.96$, for pseudo-word spelling test $=.86$ ). Pre and post test on scores on the spelling test were highly correlated (Pearson's rho $=.92$ ) and on the 
pseudo-word test reasonably highly correlated. Both test were highly correlated with a frequently used standardised spelling test, the Young Parallel Group test (spelling test with Young, Pearson's rho $=$ between .88 and .91 , depending on year group; pseudoword spelling test with Young, Pearson's rho around .7, depending on year group).

\section{Intervention}

Teachers attended a 10-session literacy course covering comprehension and morphology. The course was delivered over one school term. There were three main aspects to the morphology part of the course: an introduction to theories and research about morphology and literacy; involvement of teachers in the intervention and research process; the provisions of a practical set of materials, including lively PowerPoint slides and teachers' notes, to enable teachers to "do" explicit morphology in their classrooms. The underlying principle of the morphology materials was to help children see how words could be divided into roots and stems, each contributing to the meaning (and the spelling) of the word. Throughout the scripted sessions, children were encouraged not just to answer questions but to give reasons for their answers, often discussing and working in pairs. As morphemes often have a grammatical function (plurals, past tense of verbs, changing a verb to a noun, etc.) the children did some exercises to familiarise them with verbs, nouns and adjectives. For example, children were asked to decide if a word fitted in a sentence: e.g. 'We saw a sing in the town centre'. They were then introduced to a range of derivational morphemes, starting with prefixes and suffixes such as 'un' and 'less', that changed the meaning of a word in an obvious way. Next, they worked with inflectional morphemes that changed the type of word, e.g. teach to teacher, verb to noun. They were asked to try out stems with different beginnings and endings, always thinking about how this 
changed the meaning, and how adding morphemes changed the way a word was spelt. Does hop become hoping or hopping? Why does say have a 'y' but said have and 'i'? And does that have anything to do with baby and babies? They were asked to try to find spelling rules, for example, for when to use 'ion' and when to use 'ian'.

Prior to running the 10 -session course we had run three short in-service courses as a pilot. Feedback from these courses was that: advanced warning was needed to make a space for the use of intervention materials in the termly plan; teachers valued discussion with other teachers; provision of the theoretical and evidence base for the course content was important. This feedback was used to refine the final course. For example, teachers were advised well before the course to make space in their plans for spelling sessions. At the beginning of the course, the theoretical and evidence base was introduced following teachers' discussion of their own techniques of teaching spelling and connections made. Teachers were also provided with selected readings. The research design was discussed and teachers identified suitable control classes within their schools. They were given a seven session spelling intervention and asked to try it out in their classroom over the term. They were asked to record their experience of the sessions, and the way their pupils responded in a diary. When teachers attended the course at university, they discussed how their children did in the tests, how the sessions were going, how they would approach the next sessions, we examined samples of children's writing, we discussed how this tied in with the theoretical side and the readings, they heard from other teachers who had tried the same system, they discussed approaches to teaching spelling between themselves and we wrestled with the practicalities of handing out information, teaching materials, etc. Through this process we attempted to integrate theory and practice. 


\section{One year teacher follow-up}

In the next school year, one of the teachers who had attended the course organised a range of different spelling conditions in her school, and assessed their impact on a new cohort of children. She involved three parallel Year 4 classes. Two of these classes were tested on their spelling in the Autumn term. Thirteen weeks later, in the Spring term they were re-tested and the $3^{\text {rd }}$ parallel class was also tested. Over the next 13 weeks, she used the morphology intervention materials with her class in a special time slot $(n=23$, the morphology condition - the children had not used these materials previously). One parallel class spent the same dedicated time on spelling using materials from the National Literacy Strategy ( $n=26$, the NLS condition). In a third parallel class children followed the standard programme $(n=19$, the standard condition). All three classes were re-tested in the Summer term.

\section{Figure 1 around here}

\section{RESULTS}

\section{Phase one: Teachers' use of morphology in spelling instruction}

\section{$\underline{\text { Interviews }}$}

In the interviews, teachers mentioned a range of mistakes that children could make in spelling. The majority were attributed to problems relating to phonology (eg. problems with spelling silent letters such as the " $\mathrm{h}$ " or the "e" in "white", representing vowel sounds which could be difficult to "hear" unambiguously). Difficulty with letter blends and familiarity with the meaning of a word were also mentioned. 
However, not surprisingly, considering our selection of spelling words, teachers also mentioned error types directly related to morphemes, in particular, problems with past tense 'ed' endings, irregular past tense endings (eg. slept) and prefixes or suffixes. Overall, 1,930 statements were coded. Forty-five percent $(n=878)$ of these statements referred directly to problems with phonology. The next most significant category was morphology, which accounted for a further $20 \%(n=386)$ of teachers' statements. This is not surprising, as we know that the dominant spelling strategy is a phonological one, and eight of the 12 prompt words in the interview were chosen for reasons relating to morphemes. More interesting is the way in which the teachers discussed the role of morphemes in spelling and teaching spelling.

Despite our rigged interview, the word morpheme was conspicuous by its absence, it was not once mentioned by any of the teachers. However, teachers did refer to morphemes in other ways. The vast majority $(82 \%, n=41)$ talked about prefixes and suffixes. They also talked about past tense verbs in response to the prompt words Opened, Slept and Uncovered $(62 \%, \mathrm{n}=31)$. When teachers mentioned the "-ed" morpheme, they almost always linked it with a change in meaning. They explicitly taught their pupils that adding "-ed" changes the verb from the present to the past tense.

“Opened, they wouldn't think to put the "-ed" on the end, although we do do lots of work with past tense, but it's drip, drip, drip. We have to constantly remind them.... So, for example, we've just been to the National Gallery and we wrote it as what we were going to do, so "tomorrow we are going to go...." And then we went, so the next day, we wrote "On Monday we went to...", so we changed the whole, so it's a concrete experience. (Teacher 11) 
This term we have been focusing specifically on suffixes to do with verbs particularly, so they know that the 'ed' becomes the past tense. It's got better since we've done that actually. (Teacher 37)

When teachers referred to prefixes and suffixes other than the "-ed" ending, they were much less likely to make a link with meaning (only $36 \%$ of teachers $(n=18)$ did this). If they did talk about meaning, it was more likely to be in the context of a prefix like "un-" or "pre-", for which there is a synonym, rather than suffixes such as "-ness" or “-ion" which serve a grammatical function. It would seem that English speakers tend to be very uneasy with the subtleties of grammar.

I always like to have the prefixes change the meaning of the word and then to identify the common ones so you know for "un" you could say it makes the word opposite and looking at how it changes the word. (Teacher 36)

Well the prefix bit, the 'pre-', we do prefix work anyway so that they'd see 'pre' as a distinct part of a word that goes together and then '-pare'.... They'd all have different prefixes to work with and come back at the end and discuss how it's changed the word. Like "prepare", you'd have to find out the root of "prepare". What is the root anyway? They love things like is it called etymology? They love finding out where these words come from so it is worth it. (Teacher 20)

The majority talked about morphemes in terms of letter strings or letter patterns Teachers observed that their children spelt "richness" with a single "s", or 
"pavement" as "pavemint" or "pavemnt" and that "-ion" words are particularly tricky. Here, teachers were making use of the fact that prefixes and suffixes are frequently occurring letter chunks, which are difficult to spell by relying entirely their sound. Memory of visual patterns offers a viable spelling strategy.

Within the literacy hour there is focus on suffixes in Year 5 and in Year 3 and 4 so they would look at groups of words with the same suffix and I have some suffixes written up for display in my room as well so they can look for patterns. (Teacher 56)

I simply pulled out a whole heap of words ending in like, we had "-ness" and "-less" and what sorts of patterns could they see? And they all went "Hey, they all end in "-ness" or they all end in "-less"”. (Teacher 13)

Finally, when it came to "-ion", teachers had no difficulty in recognising that this was a real problem for children's spelling, but only three teachers referred to suffixes in this context and none of the teachers mentioned the meaning function of "-ion", changing a verb to a noun. There was a general unease about teaching "-ion" and those who had a go at describing a strategy always suggested a visual one, basically involving rote learning.

I would probably do, either learn a group of words that end in "-tion", or specifically learning "tion" as a phrase and having it displayed in class or in the word bank. And it could be anything ridiculous, it could be 'tigers itch or not', you know, it could be anything to help them remember it. (Teacher 09) 
Brainstorming work, similar endings, “-tion”, “-cian” because its exactly the same sound, it's so confusing isn't it? Some of the better spellers might put “cian” but they would probably know “-tion”. That would be a smaller mistake, that would be the ones that almost got it and they're just not familiar enough with "-tion" so there are quite different levels of mistakes. (Teacher 50)

It seems that teachers have explicit knowledge of some aspects of morphology but not others. This explicit knowledge reflects both the context in which they teach (in this case under the mantle of the NLS) and aspects of morphology that are most transparent. Many of the grammatical functions of morphemes remain implicit. More fundamentally, the fact that morphemes underpin our vocabulary, the way in which roots are used in combination with morphemes to generate many of our more complex words, is rarely explicitly mentioned or observed.

\section{$\underline{\text { Observation }}$}

Of the 88 literacy events coded from the 46 video observations, only 9 dealt with spelling. The emphasis was on phonic and visual strategies but three events had some relationship to morphology: a session on doubling consonants when adding “-ed”, “ing”, etc. (largely a phonics focus still); a session on plural spellings and a session on the prefix. The term morpheme was not used. Only the sessions on plurals and prefixes mentioned meaning. The session on plural forms was very focused and no connection was made with other examples of adding morphemes.

In this sample of teachers, teaching about morphology was rare. 


\section{Phase two - intervention effects}

\section{How Teachers Changed}

On the first session of the course, the most frequently mentioned methods of teaching spelling were:

- Look, cover, write, check (13 out of 20- two thirds of teachers mentioned this)

- Letter strings/letter patterns (12 out of 20$)$

- Spelling rules (magic "e", plurals of words like "baby"), particularly using mnemonic strategies, eg. "ought”: O u great hairy teacher (12 out of 20)

- Phonic strategies (11 out of 20)

- Learning whole words (high frequency words, technical words, words identified as difficulties for individual children) (9 out of 20)

- Proof reading of various kinds (9 out of 20)

- Spelling investigations (7 out of 20$)$

- Spelling banks and dictionaries (6 out of 20)

- Kinetic learning of various kinds (5 out of 20 )

The use of prefixes, suffixes or roots was only spontaneously mentioned four times and there was only one reference to morphemes.

We also asked the teachers to write down their definition of a morpheme. Of the 20 teachers who completed this pre-course questionnaire, a quarter knew that it was a small chunk of a word which had meaning. Other responses varied, eg.: "God knows", "something to do with spelling", the most common definition was "a unit of sound". This confirmed the findings of our earlier survey, that primary teachers have 
quite limited explicit knowledge of morphemes. One teacher reflected that much of her own knowledge of grammar was picked up rather than taught.

I learnt the majority of my English grammar indirectly. I don't consciously remember being taught present, past and future tenses in the same way as they were taught in my French classes. (French) was taught through a structure specific approach and informed my understanding of the English language. (Teacher 55)

At the end of the course we asked the teachers to give us their definition of a morpheme again. Of the 17 teachers for whom we had data at the beginning and the end of the course, three had defined a morpheme fairly accurately at the beginning and 16 out of 17 at the end. Teachers tended to consider phonological awareness as "an essential foundation in the learning of reading and spelling", but saw that teaching children about morphology also had important benefits for 7 to 11 year olds. All but one of the teachers reported that the course had changed their approaches to teaching spelling. As expected, most mentioned that they would teach more explicit morphology, making connections between spelling, grammar and meaning. However, they changed in a number of other ways too. Several teachers mentioned that they would take spelling more seriously, for example focussing one (one hour) literacy session per week on spelling and/or taking a more structured approach to teaching spelling. They also saw spelling as having more creative possibilities such as class discussions and investigations. A number of teachers thought that using computer generated materials had been good fun and effective and had encouraged them to try this again in the future. Seven out of the 17 teachers spontaneously mentioned that they would like to introduce the use of spelling journals. This was not something that 
we had suggested but something that the teachers had discussed between themselves during the course. We had hoped that the course would be an interaction between us and the teachers, but worried that in the end, the tremendous pressure of dealing with all the practicalities would squeeze this luxury out. It seems that some dialogue did go on between teachers despite everything.

We have no comprehensive information about whether or not the change in practice was sustained, but fear that in many cases it was not. Seven of the teachers wanted to work with us in the next school year, having twice termly meetings to share practice and assessing the progress of their children. In reality, teachers found it hard to attend sessions outside school once the course was completed and only three of the seven teachers systematically used the materials.

\section{The impact on their pupil's spelling}

Before the course, the children in the control classes were fairly evenly matched with the children receiving the morphology intervention, except for Year 3 where the control group were substantially better on both spelling $(\mathrm{t}=2.0, \mathrm{df}=203, \mathrm{p}<.05$, Table 2) and pseudo-word spelling $(t=2.4, \mathrm{df}=177, \mathrm{p}<.02$, Table 3$)$. Around seven weeks later, all the children had improved, but the morphology group had made larger gains than the control group (overall, three times as much). Statistical significance was assessed by fixed order regression where pre-test was entered in the first block and experimental group in the second. Overall, the morphology group had made significantly more progress than the control group on both spelling and pseudo-word spelling. The intervention showed a moderate effect size $(.50, \mathrm{~B}=3.3, \mathrm{p}<.001)$ on 
the spelling test and $.48(\mathrm{~B}=3.5, \mathrm{p}<.01)$ on the pseudo-word test $)$, which is impressive for a class level intervention.

\section{Table 2 around here}

\section{Table 3 around here}

In one very large Year 5 class (with 45 children), children had been randomly assigned to do the morphology tasks, some comprehension tasks or the standard classroom programme. This is a particularly strong design because the children were no different from each other, were getting no different treatment in class except for the interventions. In this class, the children who received the morphology tasks did significantly better than the other two groups on spelling (Fig 2; difference between groups assessed by Analysis of Variance, $\mathrm{F}=3.6, \mathrm{p}<.01$, where pre-test was entered as a co-variant) and the children who received the comprehension tasks made more progress on comprehension. The impact of the intervention does not seem to be the result of having something new but with the morphology training itself.

\section{Figure 2 around here}

\section{One year follow-up}

In the following school year, one school ran a range of different spelling conditions and assessed their impact on children's spelling gains. When not given dedicated spelling sessions, none of the classes made statistically significant gains on the 
spelling test over a period of 13 weeks. This can be seen by comparing the morphology and NLS conditions between pre-test and $1^{\text {st }}$ post-test, and the standard control between $1^{\text {st }}$ and $2^{\text {nd }}$ post-test, during which time children received standard literacy hour provision. Paired t-tests revealed no significant spelling gains. During the 13 weeks between $1^{\text {st }}$ and $2^{\text {nd }}$ post-test, some children received morphology or NLS spelling sessions in addition to their literacy hour. Both these groups of children made significant gains in spelling (morphology condition, paired $t=7.0, \mathrm{df}=22$, $\mathrm{p}<.001$; NLS condition, paired $\mathrm{t}=2.4, \mathrm{df}=25, \mathrm{p}<.02$ ). The children receiving the morphology sessions made significantly greater gains than the children receiving the NLS based sessions (controlling for pre-test, $\mathrm{B}=9.73, \mathrm{p}<.002$ ). The morphology children made significantly greater progress between $1^{\text {st }}$ and $2^{\text {nd }}$ post test than the standard control group $(\mathrm{B}=12.3, \mathrm{p}<.0001)$, with a very large effect size $=1.88$. The NLS group did not made significantly greater progress than the standard control group. It would seem that without dedicated sessions, explicit teacher knowledge is not sufficient to produce spelling gains in children. However, the sessions, paired with teacher expertise are extremely effective. The increase in the effect of the morphology intervention in the second year could be due to a longer period for intervention (13 as opposed to 7 weeks) or to the teacher's familiarity with the materials, or to a combination of both these factors.

\section{Table 4 around here}

\section{Teachers' Comments on the Intervention Process}

Generally, teachers felt the course had been a worthwhile experience both for them and their pupils, but there were some problems. 


\section{Teacher time}

Teaching a completely novel morphology lesson each week was challenging. Ideally, it would be preferable to spread the course over a longer period, though this may have resulted in less commitment. Even though the sessions had been designed to fit into teachers' existing timetabling for literacy, some found that they needed to teach the morphology activities outside the literacy hour and many teachers commented that, at least to begin with, sessions took quite a long time (half an hour or more). Shorter sessions may have been easier to integrate. It seems likely that the course led to more direct teaching of spelling, not just a change in method of direct instruction.

We had aspirations to include the teachers at all stages of the research process. Teachers were very sophisticated in their reasoning about the research. They were concerned to set up suitable comparison/control groups, they were conscious that each teacher used the morphology sessions in slightly different ways, some doing more, some less, some reinforcing learning in other parts of their literacy teaching, others not, etc. They were concerned that it was difficult to be sure that the improvements observed in their children were as a result of linking morphemes with meaning or merely due to increased exposure to letter patterns such as "-ion". However, they did not have the technical skills to analyse the data by themselves and this turned out to be too much to take on alongside running the interventions in their classrooms.

\section{Working with the children}

There were three particular concerns in working with children, familiarisation with the technology, learning time and differentiation. 
First, the use of the technology was an issue. On the whole, both teachers and children approved of the lively, interactive PowerPoint presentation of the morphology materials. In particular, it was seen as motivating for children who were more difficult to engage. However, the down sides were that, potentially, children were too passive and that some teachers found it hard to organise.

Secondly, children needed time to grasp some of the concepts and to have an opportunity to explore language. A number of teachers commented that some of the younger children struggled with the concept of noun, verb and adjective. Inflectional morphemes, those which serve a grammatical function, are more difficult to learn than derivational morphemes such as "un-", “-less" and "-ful". One teacher wrote:

In the literacy hour we do address spelling in the word and sentence level section of the hour, but is fifteen minutes a day really enough time to allow children to learn experientially and firmly concrete their knowledge? The reality of time is a big issue. Children need to have time to discover the patterns and trends for themselves and then formulate their own 'rules', as well as the time to then test their new knowledge. (Teacher 46) This teacher encouraged her pupils to take ownership of their learning and at the end of the session children discussed and evaluated their own learning. The more able children in the groups acted as experts and were encouraged to explain their thinking and the "how" part of the sessions.

When the penny drops for children they can have a unique way of explaining how they came to understand which can often help the less able children to see the light. (Teacher 46) 
The third major issue was differentiation. The teachers on the course had pupils spanning the age range 8-11 years. As mentioned above, some aspects of grammar where demanding for younger children. Some of the more able children found the tasks too easy and needed extension. Generally, children varied in the way they used the sessions, and it is likely that teachers too varied. For example, one teacher commented that the morphology sessions worked particularly well for children for whom English is an additional language.

It was clear they benefited from the direct teaching which enabled them to clarify misconceptions and underpin their existing (and sometimes shaky) knowledge of word classifications and changing meaning. (Teacher 55) She felt it was less suitable for her children with special educational needs who "did not have a broad enough basic vocabulary to benefit at the level the intervention had been set." Other teachers found the sessions suitable for children with special educational needs. This is always the tension with providing materials. On the one hand, they offer an efficient vehicle to familiarise teachers with ideas and a practical manifestation of more abstract concepts relating to their teaching. On the other hand, they will always need some adaptation, selective use or extension to take account of individual differences. 


\section{DISCUSSION}

There are two driving forces underpinning this research. The first is the power of an idea, a conceptual understanding. The second is how that idea is transformed into practice. The concept explored is the role of morphology in spelling, interesting because it has a fundamental role in the way our language is constructed, but our understanding of this concept is largely implicit.

Transforming research into teacher practice is a complicated business. In the research that is the focus of this study, the process of transformation had already begun. English policy documents identify the role of morphology in teaching spelling. However, when we looked at teachers' practice, reference to morphemes was limited and patchy. No teacher spontaneously mentioned the word morpheme, and when asked, most teachers were unaware of its meaning. This suggests the absence of an explicit knowledge of the concept of the way morphology governs the spelling construction of English. Although teachers talked about aspects of morphology, most commonly in the context of verb endings and prefixes and suffixes, they normally focused on the visual patterns, failing to make a link between this and the meaning function. Observation in the classroom confirmed that children were rarely taught about the morphological dimension of our language. 
Apparently, policy on morphology has not translated consistently into practice. Smith and Smith (1992) discuss the complex relationship between policy and research. The policy documents themselves are not a transparent reflection of existing research knowledge. In our case of morphology, layers of documentation give different messages, no doubt written by different authors with different understandings of what is important in teaching spelling and different levels of explicit knowledge of morphology. Also, "morphology" covers a very wide and complex range of morphemic influences on spelling. To a limited extent, the teachers' practice that we observed reflected the documentation on morphology fairly well. Where practical activities in the documentation emphasised the link between an inflection or a derivational morpheme and meaning, a link between morpheme and meaning was more likely to be mentioned by teachers. The documentation failed to communicate the pervasive role of morphology in spelling and teachers' existing knowledge influenced the extent to which they implemented those elements that were unambiguously described. 
Our own attempts at transforming teachers' practice were in some ways more successful than national policy. We could focus on the concept of morphology and offer materials for use in the classroom which made the role of morphology in spelling more explicit. There was little difficulty in increasing teachers' understanding of morphology. Changing their classroom practice, even in the short term, was more difficult. It is difficult to make changes to practices which are already governed by previous behaviour and a range of hierarchical structures. As Joyce and Weil (1986) have documented, the teachers themselves have to be part of the transformation. It is easy to underestimate how much effort it takes teachers to make this transformation. No materials can be taken into the classroom and used without adaptation. The teachers who worked with us had to differentiate the materials in the classroom. Access to technology varied and this influenced a number of aspects of the teaching process, medium of instruction, timing and location. Some teachers had access to computers and classroom projectors, others had not. Some could operate within the classroom, others had to use the assembly hall or a computer suite, etc. Teachers vary in their pedagogy. Some teachers encouraged children to investigate and discuss the ideas, others preferred a more formal style of pedagogy. 
Despite the difficulties, the teachers did change their practice, to varying degrees, and this had a positive impact on their pupils' spelling. The pupils of teachers attending the course made significant gains in spelling compared to children in similar classrooms receiving standard instruction. The effect size of .50 was impressive for a whole class intervention delivered by teachers just learning a technique for the first time. The intervention is quite a focussed and practical one, despite its conceptual base, and this probably contributed to its impact. Exactly what aspect of the intervention caused the change is less clear. We would like to say that increasing teachers' conceptual awareness of morphology is the explanation of their pupils' spelling gains. However, there are a number of other contenders. The classic alternative explanation is that the children did better just because they were being exposed to something new. There are a couple of reasons why this seems unlikely. The teachers of half of the control children were attending a maths course which was also exposing the pupils to novel practices. In one of the intervention classrooms, some children received the morphology materials and others comprehension materials also covered on the course. The morphology children made significant gains on spelling, the comprehension children on comprehension. Another alternative explanation for children's spelling gains is that teachers spent more classroom time teaching spelling. This was certainly an effect of the intervention. We had seen from the survey phase of our research that there is not a great deal of teaching time dedicated to spelling in the standard classroom and the teachers on our course commented that they were spending more time teaching spelling than they would normally. In the year following the course, one school clarified what aspect of our intervention was improving children's spelling. Just improving teachers' explicit knowledge of morphology was not enough. In the Autumn term, the teacher who had 
been on the course did not have an opportunity to use the morphology materials. During this term, her new group of pupils made no greater gains in spelling than the other children in the school, despite the fact that this teacher did have explicit understanding of the role of morphology. Increasing the amount of time on spelling did not explain the gains entirely either. When her class was compared with a parallel class (the NLS condition) receiving the same amount of additional spelling instruction, her morphology group made significantly more progress than the children having additional NLS spelling activities. However, additional curriculum time was helpful. Both these classes made significant spelling gains compared to a control class and to their own progress in the previous term. The ingredients for change in pupils' performance appear to be teacher knowledge and dedicated teacher time.

We conclude that it is possible to transform research into teacher practice, but we must add a cautionary note. In the year following our course, despite teachers commitment to the techniques introduced, a proportion, probably the majority, did not use them systematically. Consistent application of the techniques will require another layer of transformation back up through the policy cycle to make a more prominent place for morphology in the classroom. 


\section{Acknowledgements}

We are grateful to the Economic and Social Research Council who funded this research as part of the Teaching and Learning Research Programme. We would like to thank all the teachers who participated in our research. They were tremendously generous with their time and endlessly patient as we interviewed and videoed them and tested their children. In particular, the teachers who attended the morphology course were truly our partners in this research, testing their children, marking and entering data, teaching the interventions, nagging us about the rigour of our research and the management of the intervention sessions. Thank you all. Participant teachers and schools: Maggie Bacon, Nick Bonell, Kay Croft, Karen Henry - Kingswood Primary; Louisa Lochner - Gateway; Kathy Thornton - Kingsgate Primary; Stephen Buzzard - New End Primary; Lucinda Midgely - Linton Mead Primary; Rachel Webber- Waterside SEBD Primary; Sameena Bashir - Fullwood Primary School; Karen Bloomfield - Coppice Primary School; Caroline Havers - Mayespark Primary School; Carina Mcleod - Cleveland Junior School; Sophia Shaikh, Barbara Turner Woodlands Junior School; Deborah Walters - Christchurch Primary School; Nathalie Allexant - Gallions Primary School; Bryony Roberts - Edith Neville School. 


\section{REFERENCES}

Adey, P. (2004) The Professional Development of Teachers: Practice and Theory (London: Kluwer).

Clark, C.M. \& Peterson, P.L. (1986) Teachers' thought processes, in: M.C.

Wittrock (Ed), Handbook on Research in Teaching (3rd edition) (New York:

Macmillan), 255-296.

Department for Education and Employment (1998) The National Literacy Strategy:

Framework for teaching YR to Y6 (Suffolk: DfEE publications).

Department for Employment and Skills (2001) National Literacy Strategy: Spelling bank (London: DfES publications).

Department for Employment and Skills (2003) Year 2 and Year 3 Planning Exemplification and Spelling Programme (http://www.dfes.gov.uk).

Ehri, L. (1986) Sources and difficulty in learning to spell and read, in: M.L.Wolraich \& D. Routh (Eds) Advances in developmental and behavioural paediatrics (Greenwich, CT: JAI), Vol 7, 121-195.

Elmore, R. (1996) Getting to scale with educational practice. Harvard Educational Review, 66(1), 1-26.

Fisher, C.J., Fox, D.L. \& Paille, E. (1996) Teacher Education Research in the English Language Arts and Reading, in: J. Sikula, T. Buttery \& E. Guyton (Eds) Handbook of Research on Teacher Education (2 ${ }^{\text {nd }}$ edition) (New York: Macmillan), 410-441. 
Frith, U. (1985) Beneath the surface of developmental dyslexia, in: K. Patterson, M.

Coltheart \& J. Marshall (Eds) Surface Dyslexia (London: Lawrence Erlbaum Associates Ltd.).

Gentry, J.R. (1982) An analysis of developmental spelling in GYNS AT WRK. The Reading Teacher, 36, 192-200.

Grossman, P.L., Wilson, S. \& Shulman, L.S. (1989) Teachers of substance: Subject matter knowledge for teaching, in: M. Reynolds (Ed) Knowledge base for the beginning teacher (Elmsford, NY: Pergamon), 23-36.

Grossman, P.L. (1990) The making of a teacher: Teacher knowledge and teacher education (New York: Teachers College Press).

Henderson, E. (1985) Teaching spelling. Boston: Houghton Mifflin.

Hurry, J. (2004) Comparative Studies of Instructional Methods, in: T. Nunes \& P. Bryant (Eds) Handbook of Children's Literacy (London: Kluwer), 557-575.

Jackson, N.W. \& Coltheart, M. (2001). Routes to Reading Success and Failure (New York: Psychology Press).

Joyce, B. \& Weil, M. (1986) Models of Teaching (3rd edition) (Engelwood Cliffs, NJ, Prentice Hall). 
Karmiloff-Smith, A. (1992) Beyond modularity: A developmental perspective on cognitive science. Cambridge, MA: Bradford.

Leithwood, K., Begley, P. \& Cousins, J. (1992) Developing expert leadership for quality schools (London: Falmer Press).

National Curriculum online (2004) Programme of Study for Key Stage 2 EN3

Writing (http://www.nc.uk).

Nunes, T., Bryant, P. \& Bindman, M. (1997) Spelling Acquisition in English, in: C.

Perfetti, L. Rieben \& M. Fayol (Eds) Learning to Spell (London: Laurence Erlbaum), $151-170$.

Nunes, T., Bryant, P., \& Olsson, J. (2003) Learning morphological and phonological spelling rules: an intervention study, Scientific Studies of Reading, 7, 289-307.

O’Day, J. (1996) Incentives and student performance, in: S. Fuhrman \& J. O’Day (Eds) Rewards and reform: Creating educational incentives that work (San Francisco: Jossey-Bass).

Piaget, J. (1978) The development of though: Equilibration of cognitive structures (Oxford: Blackwell).

Shulman, L.S. (1987) Knowledge and teaching: Foundations of the new reform, Harvard Educational Review, 57(1), 1-22. 
Smith, G. \& Smith, T. (1992) From Social Research to Educational Policy:

10/65 to the Education Reform Act 1988, in: A.H. Halsey \& C. Crouch (Eds)

SocialResearch and Social Reform/ essays in honour of A.H. Halsey (Oxford:

OUP), 245-271.

Treiman, R. \& Cassar, M. (1997) Spelling Acquisition in English, in: C. Perfetti, L.

Rieben \& M. Fayol (Eds) Learning to Spell (London: Laurence Erlbaum), 61-80.

Treiman, R. Cassar, M. \& Zukowski, A. (1994) On the status of final consonant clusters in English syllables. Journal of Verbal Learning and Verbal Behavior, 23, 343-356.

Zancanella, D. (1991) Teachers reading/readers teaching: Five teachers' personal approaches to literature and their teaching of literature. Research in the Teaching of English, 25(1), 5-32. 
Table 1

Teaching Condition by Year Group

\begin{tabular}{|l|c|c|c|}
\hline Year group & $\begin{array}{c}\text { Pupils in the } \\
\text { control group }\end{array}$ & $\begin{array}{c}\text { Pupils in the } \\
\text { morphology group }\end{array}$ & Total \\
\hline Year 3 & 109 & 96 & 205 \\
\hline Year 4 & 57 & 129 & 186 \\
\hline Year 5 & 126 & 86 & 212 \\
\hline Year 6 & 54 & 29 & 83 \\
\hline Total & 346 & 318 & 686 \\
\hline
\end{tabular}


Figure 1

One year teacher follow up

13 weeks

Standard programme

3 Year 4 classes
13 weeks

1 class, Morphology intervention

1 class, NLS intervention

1 class, standard programme
Pre-test

mid Autumn

term $1^{\text {st }}$ post test

mid Spring

term $2^{\text {nd }}$ post test

mid Summer term 
Table 2

Children's scores on spelling test: by teaching condition and year group

\begin{tabular}{|l|c|c|c|c|c|c|c|c|}
\hline Year group & \multicolumn{4}{|c|}{ Pre-test } & \multicolumn{4}{c|}{ Post-test } \\
\hline & \multicolumn{2}{|c|}{ Control group } & \multicolumn{2}{c|}{$\begin{array}{c}\text { Morphology } \\
\text { group }\end{array}$} & \multicolumn{2}{c|}{ Control group } & \multicolumn{2}{c|}{$\begin{array}{c}\text { Morphology } \\
\text { group }\end{array}$} \\
\hline & mean & $(\mathrm{sd})$ & mean & $(\mathrm{sd})$ & mean & $(\mathrm{sd})$ & mean & $(\mathrm{sd})$ \\
\hline Year 3 & 64 & $(24)$ & 57 & $(23)$ & 64 & $(22)$ & 62 & $(23)$ \\
\hline Year 4 & 65 & $(25)$ & 65 & $(27)$ & 68 & $(25)$ & 70 & $(26)$ \\
\hline Year 5 & 74 & $(22)$ & 72 & $(21)$ & 76 & $(19)$ & 76 & $(20)$ \\
\hline Year 6 & 75 & $(26)$ & 76 & $(22)$ & 77 & $(24)$ & 86 & $(16)$ \\
\hline Total & 69 & $(24)$ & 65 & $(25)$ & 71 & $(23)$ & 71 & $(23)$ \\
\hline
\end{tabular}


Table 3

Children's scores on pseudo-word spelling test: by teaching condition and year group

\begin{tabular}{|l|c|c|c|c|c|c|c|c|}
\hline Year group & \multicolumn{4}{|c|}{ Pre-test } & \multicolumn{4}{c|}{ Post-test } \\
\hline & \multicolumn{2}{|c|}{ Control group } & \multicolumn{2}{c|}{$\begin{array}{c}\text { Morphology } \\
\text { group }\end{array}$} & \multicolumn{2}{c|}{ Control group } & \multicolumn{2}{c|}{$\begin{array}{c}\text { Morphology } \\
\text { group }\end{array}$} \\
\hline & mean & $(\mathrm{sd})$ & mean & $(\mathrm{sd})$ & mean & $(\mathrm{sd})$ & mean & $(\mathrm{sd})$ \\
\hline Year 3 & 52 & $(23)$ & 43 & $(26)$ & 52 & $(25)$ & 57 & $(23)$ \\
\hline Year 4 & 54 & $(27)$ & 53 & $(30)$ & 61 & $(25)$ & 57 & $(28)$ \\
\hline Year 5 & 58 & $(25)$ & 53 & $(25)$ & 61 & $(24)$ & 60 & $(24)$ \\
\hline Year 6 & 65 & $(26)$ & 64 & $(25)$ & 69 & $(25)$ & 73 & $(25)$ \\
\hline Total & 57 & $(25)$ & 51 & $(27)$ & 59 & $(25)$ & 59 & $(26)$ \\
\hline
\end{tabular}


Figure 2

Year 5 class, randomly assigned to condition

Pre and post test spelling

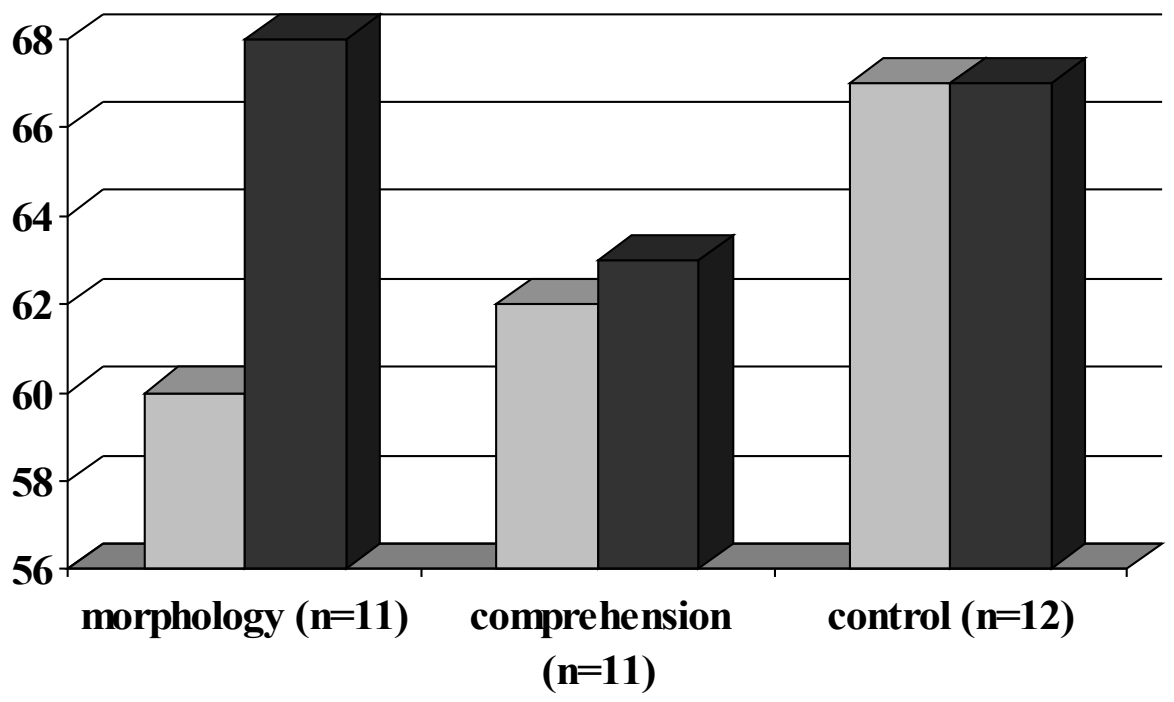


Table 4

Children's scores on spelling test: a comparison of morphology, NLS and standard conditions

\begin{tabular}{|c|c|c|c|c|c|c|}
\hline & \multicolumn{2}{|c|}{ Pre -test } & \multicolumn{2}{|c|}{$1^{\text {st }}$ post-test } & \multicolumn{2}{|c|}{$2^{\text {nd }}$ post-test } \\
\hline & mean & (sd) & mean & (sd) & mean & (sd) \\
\hline $\begin{array}{l}\text { Morphology } \\
\text { condition }(n=23)\end{array}$ & 39 & (26) & 41.5 & (29) & 56 & (29) \\
\hline $\begin{array}{l}\text { NLS condition } \\
(n=27)\end{array}$ & 42 & (27) & 44 & (29) & 49 & (29) \\
\hline $\begin{array}{l}\text { Standard condition } \\
(n=19)\end{array}$ & & & 41 & (27) & 44 & (24) \\
\hline
\end{tabular}




\section{Authors}

Jane Hurry

Senior Lecturer in Research Methods

Psychology and Human Development

Institute of Education, University of London

25 Woburn Square

London WC1H 0AA

England

Tel: +44 (0)20 7612 6931; Fax: +44 (0)20 76126304

j.hurry@ioe.ac.uk

Tamsin Curno \& Mary Parker

Research Officers

Psychology and Human Development

Institute of Education, University of London

Peter Bryant, Professor

Terezinha Nunes, Professor of Psychology

Ursula Pretzlik, Senior Research Officer

Psychology Department

Oxford Brookes University

Lucinda Midgley

Teacher 
Linton Mead Primary School

London

Correspondence should be addressed to Jane Hurry 
